\title{
Research on Extended Teaching for English in the Internet Environment
}

\author{
Wang Zhengying, Xu Miao, Hu Luping \\ Zaozhuang Vocational College of Science and Technology, Tengzhou, Shandong Province, China 277500
}

wangyuanyuan928@163.com

Keywords: Internet environment; English; extended teaching; research

\begin{abstract}
With the rapid development of modern science and technology, the Internet has been popularized and widely used in various sectors of society, and has had a profound impact on people's living habits and working methods. The education industry is no exception. The Internet has a wealth of online teaching resources to provide facilities for extended teaching for English. In the Internet environment, English teaching has a wide range of extension. The extended teaching has become the inevitable trend of the development of English in the new era with strong feasibility and maneuverability. Based on the reality, this paper first elaborates the advantages of the English extended teaching in the Internet environment, then, analyzes the problems in the extended teaching English under the Internet environment, finally, it studies the feasible strategies for the implementation of extended teaching for English in the Internet environment, hope to be of significance and values.

A lot of English teaching resources appeared in the Internet environment. In the process of English teaching, using the Internet as a material carrier, the advantage of multimedia technology was demonstrated, and various forms of English teaching were presented in a dynamic manner. Through the use of English language teaching resources in the network, it provides vivid, friendly and diversified human-computer interaction interfaces, which can timely manipulate the existing information [1]. In the Internet environment, extended learning for English is a feasible way to obtain multimedia digital information on the platform of computer by using remote communication technology. Learners share rich online resources in the network, gain learning opportunities and visual multimedia information that are across classroom time, and the English teaching space has been expanded.
\end{abstract}

\section{The advantages of extended teaching of English in the Internet Environment}

\subsection{Breaking the traditional English teaching model}

Internet-based English teaching breaks the limitations of traditional English teaching. It does not stick to the constraints of time and space. It gathers learners who shares common English learning interests in different regions to share online teaching resources. Learners choose topics of interest based on their personal characteristics, making the learning process full of motivation and fun. Internet English teaching resources will brighten and open the learning environment that is originally enclosed in the classroom, and provide equal opportunities for learners in different regions. In a sense, it maximizes the fairness of learning opportunities. The teachers fully take into account the actual situation in the actual teaching process, and make out the targeted teaching methods. This is more in line with the teaching characteristics of teaching students in accordance with their aptitude and achieves the goal of promoting the overall development of the students after the implementation of the new curriculum reform

\subsection{Inspiring learners' interest in learning English}

Internet English teaching resources are more lively and interesting. Compared with traditional English text information, Internet English resources use multimedia technology to integrate multiple functions of text, graphics, sound, and images. It fully stimulates the learner's subjective initiative, and mobilizes the various senses of the body to receive different forms of information transmission 
[2]. Through the extended teaching of Internet English, the learners' potential learning motivation and desire for knowledge are stimulated, and the students are given a new learning experience. For learners who accept different learning styles, Internet resources will always have learning methods that are suitable for differentiating students. It will inspire students' enthusiasm for learning to the greatest extent and make it easier to organize teaching.

\subsection{Providing rich online learning resources}

Learners can use the search engine to search for various effective information, download electronic documents or browse newspapers and magazines at any time according to their learning needs, and even use effective English learning software to complete online learning. Learners can directly $\log$ in to English learning related websites, contact the forefront of English teaching information, and exchange their own learning experience through the Internet. This learning environment has broadened the scope of English teaching. Teaching is no longer confined to traditional classrooms, but is more selective and operational. Teachers can also actively guide students in English teaching resources, so as to provide powerful resources for the development of extended teaching. Most of the traditional English teaching is guided by teachers' explanation. Students can only passively accept knowledge. They do not give full play to their own value in learning. The classroom atmosphere is rather boring and oppressive. However, under the Internet environment, English teaching methods and learning methods have become diversified, English teaching has become lively and agile. A large number of dynamic and visualized audio and video and pictures are displayed in the teaching process, and the classroom atmosphere is activated, which injects fresh blood into extended teaching for English.

\section{Problems of extended teaching for English in the Internet Environment}

With the advent of the Internet age, it is of practical significance to use the network to implement the extended teaching for English, and provides sufficient conditions for the teaching. However, as the double-edged sword, the Internet has inevitably brought many problems while playing its convenient role. The following is a specific analysis of this.

\subsection{Information overload in the Internet environment}

From the above we know that Internet teaching resources are the basis for the development of extended teaching for English and provide more room for extended teaching for English. Teachers search for their own available classroom materials from a variety of rich resources. At the same time, students also use the Internet to help them learn after class [3]. However, the problem of information overload also appears. Although the Internet involves various kinds of knowledge and resources related to English teaching, the resources that can actually be used are carefully selected by the experienced English teachers. Not all Internet English resources can be used by learners. Content that is not related to the course is also included in the network. Therefore, when consulting relevant learning materials, teachers and students are faced with a vast of English information and seriously hindered by a large amount of irrelevant information, which often makes them losing their way, being overwhelmed, and wasting a lot of study time in vain. In the end, it seems to read the information in the network, but in fact they failed to find the desired learning materials

\subsection{The scope of extended teaching}

In the Internet environment, the actual scope of English teaching can be expanded and extended. It is no longer the only physical form that sticks to classroom teaching to present teaching scenes, but has more options in time and space. However, under such circumstances, the teacher's class-binding force has been severely degraded and it is impossible to effectively monitor students' specific learning situations. Especially when carrying out English extended teaching, students' subjective initiative performance is more pronounced. Students with weak self-discipline awareness will magnify their disciplinary violations, disrupt the order of classroom teaching, and fail to improve the effectiveness of extended teaching. In the face of this situation, it is confusing and 
disorderly compared to the traditional English classroom instruction. Teacher supervision and restraint are weakened and students' learning effects cannot be understood timely. Under the premise of not understanding the learning effect, there may be the problem of blindly expanding the scope of teaching, which cannot effectively solve the problem of student learning results.

\subsection{Outgoing students face great challenges}

Outgoing students are more inclined to highlight themselves. They are very happy to show themselves in front of teachers and classmates, and feel comfortable facing the face-to-face communication in physical classroom teaching [4]. They often actively express their views and attitudes in front of everyone. However, conducting extended teaching for English in the Internet environment makes face-to-face communication a luxury. Outgoing students cannot express their opinions at any time and any place while sitting at the computer, which will reduce the learning enthusiasm and learning pleasure of this type of students to a certain degree. They may show tiredness and distraction, and feel powerless in English learning. Because it is not a form of English teaching that they are happy to express, these students are not interested in learning.

\section{Effective strategies for extended teaching for English in the Internet Environment}

\subsection{Defining the subjective status of students}

In the traditional English teaching process, the division of roles of teachers and students is unreasonable. However, in the Internet environment, the development of extended teaching for English should follow the new teaching concept under the new curriculum reform, turning from the teacher-led to the subjective status of students. However, this does not mean that teachers have lost their responsibility for guidance and supervision. Teachers should actively guide and assist students with practical problems encountered in the teaching process. For example, when students learn the cultural customs of Western countries, teachers use the Internet to broadcast European and American movies and videos to allow students to experience the customs differences between Chinese and Western, thereby deepening the understanding of relevant issues. Students prefer a more interesting movie when they choose Western culture custom movies. Teachers must refer to their own years of accumulated teaching experience and select videos suitable for students to watch. This will save students' choice of a variety of English teaching video resources in the Internet environment, save more effective time to start self-study, and improve the initiative and enthusiasm for learning. Therefore, when carrying out the extended teaching for English on the basis of the Internet, the teachers must guarantee the accurate positioning of their roles, change the traditional division of labor in the traditional teaching concept, and actively learn and master the teaching skills in the Internet environment so as to do their own essential work.

\subsection{Strengthening the effective interaction between teachers and students in teaching}

In traditional English teaching, there is always a "cramming education" model. Teachers are good at controlling the rhythm of the classroom, and students are in a state of one-sided acceptance of knowledge. However, in the Internet environment, this phenomenon has changed, and it has directly translated from teacher's unilateral indoctrination of knowledge into two-way interaction between teachers and students, and realized the gorgeous transformation of students-oriented English teaching [5]. Because English is a language-based course, it plays a significant role in practical activities. For example, teachers can effectively demonstrate students' autonomy and effectively interact with teachers when researching relevant issues that arise in the specific teaching process. Through the expression of different views in the discussion, teachers collect information on all aspects of the Internet, through the effective cooperation with students, they analyze the nature of the problem and conclude the final conclusion through the transmission of phenomena. Therefore, the effective interaction between teachers and students is the key link in extended teaching for English. Teachers are involved in the process of communication and discussion of students under appropriate circumstances. In the process of close two-way interaction, the overall quality of 
students has been improved and their ability to express language has been significantly improved.

\subsection{Extending from teaching to life}

Combining English extended teaching activities with students' real life helps improve teaching quality and teaching effectiveness. In the Internet environment, English teaching is gradually extended to life, and it exerts its value in life. Therefore, in the specific teaching practice activities, the problems involves more common sense of life. When teachers are instructing students in their preparatory work, they must actively understand the content they need to learn, encourage students to self-query and understand relevant Internet teaching resources [6], improve students' efficiency in preparation, thus creating a good learning environment, better linking English teaching with life and cultivating students' overall quality and ability. The use of spoken English in daily life is more, and the cultivation of language ability is the focus of teachers in extended teaching. Taking into account the needs of real life, teachers should realize the life of English teaching and make it of real practical value.

\section{Conclusions}

In summary, the resources carried under the Internet environment provide more information exchange opportunities for English teaching, which is crucial for the development of English language quality. Extended teaching for English does not require direct face-to-face communication in the Internet environment. It weakens the tension in language communication and does not require the standardization of pronunciation in real life, and provide opportunities for students to learn English independently. Classroom study time is very limited. For learners, making full use of Internet English teaching resources and finding the information needed in the Internet are helpful to cultivate their awareness of learning subjects and ultimately improve their English learning.

\section{References}

[1] Lu Haisheng. Research on the Ways of Improving the Effectiveness of Extended English Graded Reading Extracurricular Teaching under the Background of Internet Plus[J]. English Journal for Middle School Students(FLTR),2016, (4):82-83.

[2] Zhang Xiaoli. Discussion on the Reform of Public English Mixed Teaching Mode in Higher Vocational Colleges Based on "Internet +" Environment[J]. The Silk Road Vision, 2016, (25):55-56.

[3] Qiu Yanqun. Let Virtual Extend Reality--Extend Mobile Learning in English Class Based on Applications such as Mobile Phone or $\mathrm{PAD}[\mathrm{J}]$. Education in Guangdong (vocational education), 2017, (7):76-78.

[4] He Minglie. Research on Teacher's Role in Experiencing English Teaching in Network Environment[J]. Overseas English,2017, (12):4-5.

[5] Qiu Yue. Internet-based Extended Teaching for English[J]. Journal of Changchun Institute of Education, 2014, (12):149-149,153.

[6] Liu Qing. Research and Practice of WeChat in College Extended Teaching for English[J]. Journal of Exam Weekly,2015, (71):94-95,96. 